\title{
Generalized anxiety disorder and the Hamilton Anxiety Rating Scale in Parkinson's disease
}

\author{
Arthur Kummer ${ }^{1}$, Francisco Cardoso ${ }^{2,3}$, Antonio Lucio Teixeira 1,3
}

\begin{abstract}
Anxiety is common in Parkinson's disease (PD), but studies concerning specific anxiety disorders are scarce. Essential psychometric properties of anxiety rating scales are also lacking. Objective: To investigate general anxiety disorder (GAD) in PD and psychometric properties of the Hamilton Anxiety Rating Scale (Ham-A). Method: Ninety-one PD patients underwent neurological and psychiatric examination, which included the MINI-Plus, the Ham-A and the Hamilton Depression Rating Scale (Ham-D). Results: GAD was present in $30.8 \%$ of PD patients. Patients with GAD had longer disease duration $(p=0.044)$ and were in use of higher doses of levodopa $(p=0.034)$. They also tended to have more motor fluctuations and dyskinesias. The group with GAD scored higher in Ham-A ( $p<0.001)$, in the somatic $(p=0.004)$ and psychic $(p<0.001)$ subscales of Ham-A, and in Ham-D $(p=0.004)$. The Ham-A showed good internal consistency (Cronbach's alpha=0.893) and a cutoff score of 10/11 is suggested to screen for GAD. Conclusion: GAD is frequent in PD and the Ham-A may be a useful instrument to screen for this disorder.

Key words: Parkinson's disease, anxiety, generalized anxiety disorder, rating scales, psychometrics, clinimetrics.
\end{abstract}

Transtorno de ansiedade generalizada e a Escala de Ansiedade de Hamilton na doença de Parkinson

\section{RESUMO}

Ansiedade é comum na doença de Parkinson (DP), mas estudos sobre transtornos de ansiedade específicos são ainda escassos. Faltam também estudos sobre propriedades psicométricas essenciais das escalas de ansiedade. Objetivo: Investigar o transtorno de ansiedade generalizada (TAG) na DP e propriedades psicométricas da Escala de Ansiedade de Hamilton (Ham-A). Método: Noventa e um pacientes com DP se submeteram a exames neurológico e psiquiátrico, que incluiu o MINI-Plus, a Ham-A e a Escala de Depressão de Hamilton (Ham-D). Resultados: TAG esteve presente em 30,8\% dos participantes. Pacientes com TAG tinham maior duração de doença $(p=0,044)$ e estavam em uso de maiores doses de levodopa $(p=0,034)$. Também havia uma tendência desses pacientes terem mais flutuações motoras e discinesias. $O$ grupo com TAG pontuou mais alto na Ham-A ( $p<0,001)$, nas subescalas somática $(p<0,001)$ e psíquica da Ham-A $(p<0,001)$, e na

\section{Correspondence}

Arthur Kummer

Rua Bolívia 222 / 102

30330-360 Belo Horizonte MG - Brasil

E-mail: r2kummer@hotmail.com

\section{Support}

This study was partly funded by Conselho Nacional de Desenvolvimento Científico e Tecnológico (CNPq, Brazil) and Fundação de Amparo à Pesquisa do Estado de Minas Gerais (FAPEMIG, Brazil)

Received 22 November 2009

Received in final form 29 December 2009 Accepted 8 January 2010 Ham-D ( $p=0,004)$. A Ham-A mostrou boa consistência interna (alfa de Cronbach=0,893) e um ponto de corte de 10/11 é sugerido para triar o TAG. Conclusão: TAG é freqüente na DP e a Ham-A pode ser um instrumento útil para triar esse transtorno.

Palavras-chave: doença de Parkinson, ansiedade, transtorno de ansiedade generalizada, escalas, psicometria, clinimetria.

Parkinson's disease (PD) is a prevalent chronic neurological disease which may affect up to $3.3 \%$ of people older than $64^{1}$.
Its main pathological findings are the loss of nigral dopaminergic neurons and the presence of Lewy bodies in the remaining

${ }^{1}$ Neuropsychiatric Branch, Neurology Unit, University Hospital, Federal University of Minas Gerais (UFMG), Belo Horizonte MG, Brazil; ${ }^{2}$ Movement Disorders Clinic, University Hospital, UFMG; ${ }^{3}$ Department of Internal Medicine, School of Medicine, UFMG. 
neurons. Diagnostic criteria for clinically definite PD include the presence of at least two asymmetric motor signs (bradykinesia, resting tremor and rigidity) and a definitive response to levodopa ${ }^{2}$. Besides PD motor signs, neuropsychiatric disorders have been recognized as a matter of concern.

Anxiety in PD is extremely common. Up to $67 \%$ of PD patients present clinically significant anxiety symptoms ${ }^{3}$. The frequency of generalized anxiety disorder (GAD) and panic disorder in PD has been estimated to be close to $30 \%{ }^{4,5}$, while up to $50 \%$ of PD patients may suffer from social phobia ${ }^{6}$. Anxiety in PD is associated with a worse quality of life, although it has been proposed that anxiety is not related to the severity of motor symptoms. ${ }^{8}$. In fact, as observed for depressive disorders, anxiety can precede motor signs by several years ${ }^{9}$. However, it is possible that anxiety worsens motor symptom, which could by turn increase anxiety ${ }^{7}$. Anxiety is also highly comorbid with depressive disorders ${ }^{10}$.

The main feature of anxiety is the inappropriate feeling of apprehension, preoccupation or fear. Cognitive and somatic changes are also present. Some symptoms may resemble PD symptoms, such as autonomic symptoms, fatigue, muscle tension, insomnia, attention problems and agitation which may be mistaken by dyskinesia or akathisia.

Several instruments to assess anxiety are already employed in PD, but essential psychometric information is still necessary to consider these instruments valid and reliable in this context ${ }^{11}$. The Hamilton Anxiety Rating Scale (Ham-A) ${ }^{12}$ is the best-known instrument designed to assess anxiety. Nevertheless, one major criticism of this scale is that it is heavily weighted toward somatic symptoms, possibly making it difficult to distinguish between symptoms of anxiety and PD symptoms. Furthermore PD patients could be more likely to endorse somatic items on Ham-A because of the characteristics of the disease and not necessarily because they are anxious. Hence, it is uncertain whether the somatic component of Ham-A detracts from its reliability in PD patients. Thus the objective of this study was to study general anxiety disorder (GAD) in PD, and to determine the psychometric properties of Ham-A and its internal consistency in PD patients with GAD. It must be mentioned that most of the individuals of this study also participated in a previous study where the frequency of a range of psychiatric disorders was compared between patients with early-onset and typical-onset $\mathrm{PD}^{4}$. In the current study, the investigation of the relationship between GAD and sociodemographic and clinical variables was deepened.

\section{METHOD}

This cross-sectional study included 91 (54 men; 37 women) consecutive patients with PD. Those patients are regularly attended at the Movement Disorders Clinic of the Federal University of Minas Gerais (UFMG), Brazil, which is part of the public National Health Service system. After their appointment with their neurologist, patients were invited to participate in this study. These subjects are not taking part in any clinical trial. Participants did not receive any kind of compensation. No patient refused to participate. This study was approved by the local ethics committee, and all subjects gave their informed consent.

PD was diagnosed according to the United Kingdom Parkinson's Disease Society Brain Bank clinical diagnostic criteria ${ }^{13}$. Patients with previous neurosurgery, other neurologic disorder or delirium and dementia were excluded. Dementia was diagnosed according to DSM-IV diagnostic criteria and to the score obtained in the MiniMental State Examination (MMSE) adapted for the Brazilian population $^{14}$.

Demographic and clinical data were obtained. Patients underwent a psychiatric and neurological examination. Psychiatric examination included a structured psychiatric interview (MINI-Plus) ${ }^{15}$ which was used to diagnose psychiatric disorders by a trained psychiatrist. In addition, an independent interviewer administrated the scales Hamilton Anxiety Rating Scale (Ham-A) $)^{12}$ and the Hamilton Depression Rating Scale (Ham-D) ${ }^{16}$.

The Ham-A is a 14-item clinician-rated instrument designed to assess and quantify severity of anxiety. Each item is rated on a five-point Likert-type scale ranging 0 to 4, with higher scores indicating more severe anxiety. Although the scale assesses a broad range of symptoms that are common to all eight of the DSM-IV Anxiety Disorders, it is most often used to assess severity of $\mathrm{GAD}^{17}$. Ham-A is comprised of a psychic and a somatic subscale. The psychic subscale (items 1-6 and 14) addresses the more subjective cognitive and affective complaints of anxiety (e.g., anxious mood, tension, fears, difficulty concentrating), and is particularly useful in assessing the severity of GAD. The somatic component (items 7-13) emphasizes features of GAD such as autonomic arousal, respiratory, gastrointestinal and cardiovascular symptoms. No information on its clinimetric properties in PD patients is available ${ }^{11}$.

Neurological examination included the MMSE, the Unified Parkinson's Disease Rating Scale (UPDRS), the Hoehn-Yahr Scale (HY), and the Schwab-England Scale of Activities of Daily Living (SES). MMSE was used to assess the general cognitive function of the participants and to help the authors to rule out dementia ${ }^{14}$. The UPDRS is currently the most widely accepted scale used to assess PD severity ${ }^{18}$. It has 3 subscales: UPDRS I - Mentation, Behavior, and Mood (range 0-16); UPDRS II - Activities of Daily Living (ADL) (range 0-52) and UPDRS III 
- Motor Examination (range 0-108). Each item is scored on a scale from 0 to 4 . A total of 176 points is possible, with 176 representing maximal (or total) disability and 0 representing no disability. The HY was used to estimate disease stages ${ }^{19}$. This instrument classifies PD patients in five stages according to the body distribution of symptoms and dependency. Patients in stage I are mildly affected, while in stage $V$ they are bedridden. Disability in performing activities of daily living was assessed with the $\mathrm{SES}^{20}$. The SES is a percentage scale divided into deciles, with $100 \%$ representing completely normal function and $0 \%$ representing total helplessness.

Comparisons of categorical data between the groups of patients with and without GAD were performed using Fisher's exact test. The Shapiro-Wilk test was used to assess normality of data. The Mann-Whitney $U$ test was employed for continuous variables. Spearman's rho test was used to assess correlation. Ham-A was evaluated by their "receiver operating characteristics" curve (ROC curve) for identifying the single cut-off point that better discriminates between patients with and without GAD. Cronbach's coefficient alpha, item-total (corrected itemtotal correlation) and inter-item correlations (Spearman's $\rho$ rank correlation coefficients) were computed to ascertain internal consistency of Ham-A. All p-values were two-tailed and a significance level of 0.05 was chosen. Statistical analysis was performed using the SPSS v15.0 software (SPSS Inc., Chicago, IL, USA).

\section{RESULTS}

Patients had a mean age of $57.2 \pm 10.5$ years and a mean educational level of $5.4 \pm 3.7$ years. A significant proportion of patients were retired (23.1\%) or receiving social security disability compensation (47.3\%), and just $20.9 \%$ of them were working. The mean age of PD onset was $48.4 \pm 11.0$ years and the mean disease duration was
$8.8 \pm 4.9$ years. Neurological examination showed that severity of disease according to UPDRS was moderate in most patients (mean $\pm \mathrm{SD}=49.4 \pm 25.3$ ). HY disease staging ranged from 1 to 4 , with a median of 2 . Percentile ratings on the SES suggested relatively independent functioning of the patients (mean $\pm \mathrm{SD}=81.4 \pm 13.0 \%$ ). Sixty-two patients $(68.1 \%)$ were in use of l-dopa. Fourteen patients (15.4\%) were in use of benzodiazepines, while 33 (36.3\%) were in use of antidepressants.

The frequency of GAD was $30.8 \%(n=28)$. Presence of GAD was not influenced by gender $(\mathrm{p}=0.110)$, occupational status ( $\mathrm{p}=0.875)$, age $(\mathrm{p}=0.962)$, educational level $(p=0.865)$, or age of disease onset $(p=0.294)$. Patients with and without GAD did not differ in disease severity $(p=0.161)$, disease stage $(p=0.203)$, performance in activities of daily living ( $\mathrm{p}=0.310)$, or cognitive performance $(p=0.738)$. Nevertheless patients with GAD had longer disease duration $(\mathrm{p}=0.044)$ and were in use of higher doses of levodopa ( $\mathrm{p}=0.034)$, although the use of levodopa was not associated with GAD ( $\mathrm{p}=0.466)$. GAD also tended to be associated with the presence of dyskinesias $(\mathrm{p}=0.072)$ and motor fluctuations $(\mathrm{p}=0.080)$, but not with wearing off phenomena.

Patients with GAD had more frequently social anxiety disorder and a history of bipolar disorder (Table 1). The group with GAD also scored higher both in Ham-A $(\mathrm{p}<0.001)$ and Ham-D $(\mathrm{p}=0.004)$. Patients with GAD scored higher in both the somatic $(\mathrm{p}=0.004)$ and psychic $(\mathrm{p}<0.001)$ subcales of Ham-A (Table 2). The Ham-A and the Ham- $D$ were highly correlated $(r=0.830, p<0.001)$. The Ham-A also correlated with UPDRS $(r=0.425, \mathrm{p}<0.001)$, HY $(r=0.266, p=0.011)$ and SES $(r=-0.393, p<0.001)$. However, when we divided the sample in groups with and without GAD, the Ham-A maintained its associations with UPDRS, HY and SES only in the group without GAD (Table 3). Even in the group without GAD, this associa-

Table 1. Frequency of psychiatric disorders diagnosed with Mini-Plus and scores in psychometric scales in Parkinson's disease patients ( $n=90$ ) with and without generalized anxiety disorders (GAD).

\begin{tabular}{|c|c|c|c|}
\hline & $\begin{array}{l}\text { With GAD } \\
(n=28)\end{array}$ & $\begin{array}{l}\text { Without GAD } \\
\qquad(n=63)\end{array}$ & $\mathrm{p}$ value \\
\hline Major depression & $11(39.3 \%)$ & $17(26.9 \%)$ & 0.325 \\
\hline Dysthymia & $7(25.0 \%)$ & $6(9.5 \%)$ & 0.100 \\
\hline Bipolar disorders & $4(14.3 \%)$ & $1(1.6 \%)$ & 0.030 \\
\hline Social anxiety disorder & $19(67.8 \%)$ & $26(41.3 \%)$ & 0.024 \\
\hline Panic disorder & $3(10.7 \%)$ & $3(4.8 \%)$ & 0.367 \\
\hline Obsessive-compulsive disorder & $5(17.8 \%)$ & $7(11.1 \%)$ & 0.503 \\
\hline Psychosis & $6(21.4 \%)$ & $5(7.9 \%)$ & 0.087 \\
\hline Ham-A (mean $\pm S D)$ & $17.9 \pm 7.7$ & $10.6 \pm 9.8$ & $<0.001$ \\
\hline Ham-D (mean $\pm S D)$ & $17.5 \pm 8.3$ & $12.1 \pm 8.0$ & 0.004 \\
\hline
\end{tabular}

Ham-A: Hamilton Anxiety Rating Scale; Ham-D: Hamilton Depression Rating Scale; SD: standard deviation. 
Table 2. Scores of patients with and without generalized anxiety disorders (GAD) in the Hamilton Anxiety Rating Scale (Ham-A) and in its subscales.

\begin{tabular}{lccc}
\hline & $\begin{array}{c}\text { With GAD } \\
(\mathrm{n}=\mathbf{2 8})\end{array}$ & $\begin{array}{c}\text { Without GAD } \\
(\mathrm{n}=63)\end{array}$ & p value \\
\hline Ham-A (mean \pm SD) & $17.9 \pm 7.7$ & $10.5 \pm 9.7$ & $<0.001$ \\
Ham-A, psychic subscale (mean \pm SD) & $9.4 \pm 4.4$ & $4.7 \pm 4.7$ & $<0.001$ \\
Ham-A, somatic subscale (mean $\pm S D)$ & $8.5 \pm 4.6$ & $5.8 \pm 5.4$ & 0.004 \\
\hline
\end{tabular}

SD: standard deviation.

Table 3. Analyses of bivariate correlations between clinical and demographic variables and the scores of patients with and without generalized anxiety disorders (GAD) in the Hamilton Anxiety Rating Scale (Ham-A) and in its subscales.

\begin{tabular}{|c|c|c|c|c|c|c|}
\hline & \multicolumn{3}{|c|}{ With GAD $(n=28)$} & \multicolumn{3}{|c|}{ Without GAD $(n=63)$} \\
\hline & Ham-A & $\begin{array}{c}\text { Ham-A, psychic } \\
\text { subscale }\end{array}$ & $\begin{array}{c}\text { Ham-A, somatic } \\
\text { subscale }\end{array}$ & Ham-A & $\begin{array}{c}\text { Ham-A, psychic } \\
\text { subscale }\end{array}$ & $\begin{array}{c}\text { Ham-A, somatic } \\
\text { subscale }\end{array}$ \\
\hline Age & $\begin{array}{l}r=0.140 \\
p=0.598\end{array}$ & $\begin{array}{l}r=0.120 \\
p=0.543\end{array}$ & $\begin{array}{l}r=0.043 \\
p=0.828\end{array}$ & $\begin{array}{c}r=-0.068 \\
p=0.596\end{array}$ & $\begin{array}{c}r=-0.189 \\
p=0.138\end{array}$ & $\begin{array}{l}r=0.013 \\
p=0.920\end{array}$ \\
\hline Educational level & $\begin{array}{c}r=-0.191 \\
p=0.331\end{array}$ & $\begin{array}{c}r=-0.349 \\
p=0.069\end{array}$ & $\begin{array}{l}r=0.026 \\
p=0.897\end{array}$ & $\begin{array}{c}r=-0.041 \\
p=0.747\end{array}$ & $\begin{array}{c}r=-0.086 \\
p=0.502\end{array}$ & $\begin{array}{l}r=-0.127 \\
p=0.321\end{array}$ \\
\hline Age of disease onset & $\begin{array}{l}r=0.101 \\
p=0.609\end{array}$ & $\begin{array}{l}r=0.103 \\
p=0.604\end{array}$ & $\begin{array}{l}r=-0.030 \\
p=0.881\end{array}$ & $\begin{array}{c}r=-0.106 \\
p=0.409\end{array}$ & $\begin{array}{l}r=-0.237 \\
p=0.061\end{array}$ & $\begin{array}{l}r=-0.021 \\
p=0.869\end{array}$ \\
\hline Disease duration & $\begin{array}{l}r=0.041 \\
p=0.834\end{array}$ & $\begin{array}{l}r=0.120 \\
p=0.543\end{array}$ & $\begin{array}{c}r=-0.004 \\
p=0.985\end{array}$ & $\begin{array}{l}r=0.152 \\
p=0.234\end{array}$ & $\begin{array}{l}r=0.154 \\
p=0.229\end{array}$ & $\begin{array}{l}r=0.149 \\
p=0.244\end{array}$ \\
\hline UPDRS & $\begin{array}{l}r=0.180 \\
p=0.358\end{array}$ & $\begin{array}{l}r=0.117 \\
p=0.552\end{array}$ & $\begin{array}{l}r=0.118 \\
p=0.548\end{array}$ & $\begin{array}{c}r=0.527 \\
p<0.001 *\end{array}$ & $\begin{array}{c}r=0.460 \\
p<0.001^{*}\end{array}$ & $\begin{array}{c}r=0.496 \\
p<0.001 *\end{array}$ \\
\hline $\mathrm{HY}$ & $\begin{array}{l}r=0.070 \\
p=0.722\end{array}$ & $\begin{array}{l}r=0.216 \\
p=0.269\end{array}$ & $\begin{array}{c}r=-0.089 \\
p=0.653\end{array}$ & $\begin{array}{c}\mathrm{r}=0.323 \\
\mathrm{p}=0.010^{*}\end{array}$ & $\begin{array}{l}r=0.244 \\
p=0.054\end{array}$ & $\begin{array}{c}r=0.324 \\
p<0.001^{*}\end{array}$ \\
\hline SES & $\begin{array}{c}r=-0.145 \\
p=0.463\end{array}$ & $\begin{array}{l}r=-0.121 \\
p=0.538\end{array}$ & $\begin{array}{l}r=-0.117 \\
p=0.552\end{array}$ & $\begin{array}{l}r=-0.512 \\
p<0.001^{*}\end{array}$ & $\begin{array}{l}r=-0.437 \\
p<0.001^{*}\end{array}$ & $\begin{array}{c}r=0.500 \\
p<0.001^{*}\end{array}$ \\
\hline Ham-D & $\begin{array}{l}r=0.657 \\
p<0.001\end{array}$ & $\begin{array}{l}r=0.762 \\
p<0.001\end{array}$ & $\begin{array}{l}r=0.353 \\
p=0.065\end{array}$ & $\begin{array}{c}\mathrm{r}=0.869 \\
\mathrm{p}<0.001^{*}\end{array}$ & $\begin{array}{c}r=0.837 \\
p<0.001^{*}\end{array}$ & $\begin{array}{c}r=0.807 \\
p<0.001^{*}\end{array}$ \\
\hline MMSE & $\begin{array}{c}r=-0.224 \\
p=0.253\end{array}$ & $\begin{array}{c}r=-0.140 \\
p=0.476\end{array}$ & $\begin{array}{c}r=-0.173 \\
p=0.378\end{array}$ & $\begin{array}{c}r=-0.116 \\
p=0.336\end{array}$ & $\begin{array}{l}r=0.020 \\
p=0.879\end{array}$ & $\begin{array}{c}r=-0.199 \\
p=0.119\end{array}$ \\
\hline
\end{tabular}

UPDRS: Unified Parkinson's Disease Rating Scale; HY: Hoehn-Yahr Staging Scale; SES: Schwab and England Activities of Daily Living Scale; Ham-D: Hamilton Depression Rating Scale; MMSE: Mini-Mental State Examination. *Statistical significance disappears when controlling for depressive symptoms (Ham-D).

tion disappeared after controlling for depressive symptoms as assessed by the Ham-D. Indeed, major depression did associate with UPDRS ( $\mathrm{p}=0.011), \mathrm{HY}(\mathrm{p}=0.008)$ and SES ( $\mathrm{p}=0.025)$, revealing their multicollinearity. The somatic and the psychic subscales correlated with UPDRS $(\mathrm{r}=0.382, \mathrm{p}<0.001$ and $\mathrm{r}=0.387, \mathrm{p}<0.001$, respectively) and SES $(r=-0.382, p<0.001$ and $r=-0.333, p=0.001$, respectively), but only the psychic correlated with $\mathrm{HY}(\mathrm{r}=0.271$, $\mathrm{p}<0.009$ and $\mathrm{r}=0.198, \mathrm{p}<0.060$, respectively). Again, when the sample was divided in groups with and without GAD these correlations were maintained only in the group without GAD (Table 3), but these correlations also disappeared after controlling for depression.

A ROC curve analysis suggested that a cutoff score of $10 / 11$ provided the best values of sensitivity and specificity in this sample. This cutoff score provided a sensitivity of $85.7 \%$, a specificity of $63.5 \%$, a positive predictive value of $51.1 \%$ and a negative predictive value of $90.9 \%$, with an area under the curve of 0.774 (Figure). A cutoff score of $13 / 14$ provided the best balance between sensitivity and specificity ( $71.4 \%$ and $74.6 \%$, respectively).

The Cronbach's alpha for the Ham-A was 0.893. All Ham-A items were significantly and positively associated with total Ham-A score (Table 2). The psychic and the somatic subscales also showed good internal consistency (Cronbach's alpha of 0.829 and 0.799 , respectively). When single items were excluded from the Ham-A, internal consistency reliability did not improve in a meaningful way (Table 4).

\section{DISCUSSION}

Just a few studies investigated GAD in PD and most of them had small samples. The frequency of GAD ranged from $4.2 \%$ to $40 \% \%^{4,8,10,21-24}$. The frequency of GAD in the 
Table 4. Corrected item-total correlations and Cronbach's alpha if item is deleted from the Hamilton Anxiety Rating Scale (Ham-A).

\begin{tabular}{lcc}
\hline & $\begin{array}{c}\text { Corrected item } \\
\text { Total correlation }\end{array}$ & $\begin{array}{c}\text { Alpha if item } \\
\text { Deleted }\end{array}$ \\
\hline 1. Anxious mood & 0.694 & 0.879 \\
2. Tension & 0.762 & 0.876 \\
3. Fears & 0.432 & 0.890 \\
4. Insomnia & 0.466 & 0.890 \\
5. Difficulties in concentration and memory & 0.506 & 0.888 \\
6. Depressed mood & 0.713 & 0.878 \\
7. General somatic symptoms: muscular & 0.492 & 0.889 \\
8. General somatic symptoms: sensory & 0.644 & 0.881 \\
9. Cardiovascular symptoms & 0.589 & 0.884 \\
10. Respiratory symptoms & 0.673 & 0.881 \\
11. Gastro-intestinal symptoms & 0.491 & 0.888 \\
12. Genito-urinary symptoms & 0.421 & 0.893 \\
13. Other autonomic symptoms & 0.641 & 0.882 \\
14. Behavior during interview & 0.637 & 0.885 \\
\hline
\end{tabular}

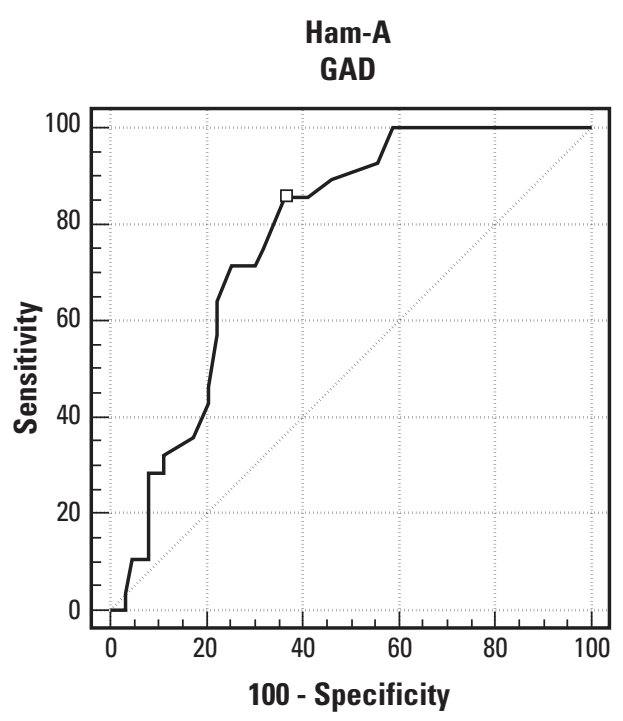

Figure. ROC curve ("receiver operating characteristics curve") of the 15 Hamilton Anxiety Rating Scale (Ham-A) for detecting general anxiety disorder in patients with Parkinson's disease.

current study was of $30.8 \%$. Risk factors associated with GAD are still unknown. In most of the studies, authors investigated factors associated with anxiety in general, but not factors specifically associated with GAD.

Many studies have found an association between anxiety and depression ${ }^{10,21,23,25}$. Although the higher frequency of depressive disorders in patients with GAD did not reach statistical significance in the current study, the Ham-A correlated strongly with Ham-D. Similarly, Starkstein et al. found that the severity of anxiety in PD (also measured with the Ham-A) correlated with depression severity ${ }^{23}$. In another study, Nuti et al. detected a trend for higher scores in the Ham-A in depressed PD patients than in depressed controls ${ }^{21}$.

In our study, the Ham-A also associated with disease severity, advanced disease stages and worse performance in daily activities, especially in the group without GAD. Nevertheless, these correlations disappeared after controlling for the Ham-D scores. Indeed, major depression was associated with disease severity, advanced disease, a worse performance in daily activities. The lack of association between anxiety and severity of disease or degree of disability is in line with some previous studies ${ }^{26}$. The initial association between GAD and these clinical variables may have occurred because Ham-A strongly correlates with Ham-D, which has been pointed out by some authors as a low discriminant validity of the Ham- $\mathrm{A}^{27}$.

The relationship between anxiety and antiparkinsonian medications is still a matter of debate. While some authors described an association between anxiety and ldopa $^{28}$, some did not ${ }^{8,10}$. We observed that GAD associated with higher doses of 1-dopa. A number of studies have also found a relationship between anxiety and "onoff" phenomena. It seems that patients are more prone to experience anxiety during "off periods ${ } 8,24,28-30$. Although GAD tended to associate with motor fluctuations, it was not possible to investigate whether anxiety is increased during "off" periods as suggested by other studies. Patients with GAD also tended to experience more dyskinesias, which is in line with Menza et al. who detected higher levels of anxiety in patients with dyskinesias ${ }^{29}$. However, the previously observed association between anxiety and fluctuations or dyskinesias probably refers to a 'pha- 
sic' anxiety, possibly due to a sudden fall/rise in dopaminergic brain levels during these periods ${ }^{22}$. Phasic influences on affective state in PD are often associated with antiparkinsonian medication. The way GAD, a type of 'tonic' anxiety state, is related with duration of illness, disease severity, advanced disease stages, higher doses of antiparkinsonian medication and thus more side effects deserves additional investigation.

In addition to the role of dopamine in anxiety disorders in PD, changes in noradrenergic, serotonergic and gabaergic pathways are also probably implicated in the neurobiology of these disorders ${ }^{31}$. Patients with PD with a short allele in the promoter region of the serotonin transporter gene have more anxiety than patients with the long allele variant ${ }^{32}$. Moreover, PD patients are unusually susceptible to yohimbine-induced panic attacks ${ }^{33}$. Yohimbine is an alpha 2-adrenergic antagonist that can induce panic attacks in vulnerable individuals. It has been hypothesized that the dopaminergic deficit would disinhibit locus ceruleus firing, determining anxiety symptoms.

Accurate definition and measurement of psychiatric symptoms are extremely important in clinical and research settings. There are many scales for the assessment of anxiety, but scarce information about their usefulness in PD patients exists. In a recent review of scales to assess anxiety in PD, the Steering Committee of the Movement Disorder Society Task Force on Rating Scales for PD concluded that none of the reviewed anxiety scales can be recommended for use in PD populations due to lack of essential information on psychometric properties ${ }^{11}$.

In the current study we showed that the Ham-A, one of the most commonly used anxiety rating scale, has good internal consistency in PD. The scale is frequently criticized because it is highly weighted towards the somatic symptoms of anxiety. This characteristic of Ham-A would be particularly problematic in chronic diseases, such as PD. However, both the somatic and the psychic subscales have good internal consistency. Patients with GAD also scored higher than patients without this anxiety disorder in both subscales, suggesting that anxiety in PD may not be a somatic artifact. It should be mentioned that, for depression, instruments weighted towards somatic symptoms may sometimes have even better psychometric properties than scales without physical items ${ }^{34}$. Nevertheless, future studies are needed to better determine how somatic symptoms overlap or not with anxiety symptoms in PD. A ROC curve analysis showed that a cutoff score of 10/11 could be used to screen for GAD in PD. It must be emphasized, however, that the scale should not be used as a diagnostic tool as it is not specific for GAD and seems to present a low positive predictive value. Future studies must also investigate in PD the validity of instruments specifically designed to assess GAD.
There are also some important limitations in this study which must be mentioned. This study included a relatively small sample size and with some particular features. A significant proportion of patients have early-onset $\mathrm{PD}$, which is evident by the low mean age of disease onset. Moreover, patients were recruited in a tertiary center, where more complex patients are usually attended. These characteristics of our sample may have some implication in the external validity of our study. The lack of a control group of healthy individuals or patients with other chronic disease is also critical. However, the consecutive sampling, the assessment of patients by experienced clinicians and the use of internationally validated instruments are strengths of this study. We hope that future studies will overcome the limitations of the current study.

In conclusion, anxiety disorders are common in PD and almost a third of PD patients may be diagnosed with GAD. Furthermore, patients without GAD may still score relatively high in Ham-A. As Ham-A in unspecific for GAD, these patients may be suffering from another anxiety disorder or even suffer from clinically significant symptoms of anxiety without fulfilling criteria for a formal psychiatric disorder. Clinicians should also be aware of a potential association among increased dosages of levodopa, the presence of motor fluctuation and dyskinesia, and higher levels of anxiety. The Ham-A is a reliable instrument to assess anxiety in PD and a cutoff score of 10/11 can be used to screen for GAD.

\section{REFERENCES}

1. Barbosa MT, Caramelli P, Maia DP, et al. Parkinsonism and Parkinson's disease in the elderly: a community-based survey in Brazil (the Bambui study). Mov Disord 2006;21:800-808.

2. Samii A, Nutt JG, Ransom BR. Parkinson's disease. Lancet 2004:363:1783-1793.

3. Chagas MHN, Tumas V, Loureiro SR, Côrrea ACL, Nakabayashi TIK, Crippa JAS. Does the association between anxiety and Parkinson's disease really exist? A literature review. Curr Psychiatry Rev 2009;5:29-36.

4. Kummer A, Cardoso F, Teixeira AL. Frequency of psychiatric disorders in young-onset Parkinson's disease does not differ from typical-onset Parkinson's disease. Parkinsonism Relat Disord 2009;15:153-155.

5. Lauterbach EC, Freeman A, Vogel RL. Correlates of generalized anxiety and panic attacks in dystonia and Parkinson disease. Cogn Behav Neurol 2003;16:225-233.

6. Kummer A, Cardoso F, Teixeira AL. Frequency of social phobia and psychometric properties of the Liebowitz social anxiety scale in Parkinson's disease. Mov Disord 2008;23:1739-1743.

7. Rahman S, Griffin HJ, Quinn NP, Jahanshahi M. Quality of life in Parkinson's disease: the relative importance of the symptoms. Mov Disord 2008;23:1428-1434.

8. Stein MB, Heuser IJ, Juncos JL, Uhde TW. Anxiety disorders in patients with Parkinson's disease. Am J Psychiatry 1990;147:217-220.

9. Shiba M, Bower JH, Maraganore DM, et al. Anxiety disorders and depressive disorders preceding Parkinson's disease: a case-control study. Mov Disord 2000;15:669-677.

10. Menza MA, Robertson-Hoffman DE, Bonapace AS. Parkinson's disease and anxiety: comorbidity with depression. Biol Psychiatry 1993;34:465-470.

11. Leentjens AF, Dujardin K, Marsh L, et al. Anxiety rating scales in Parkinson's disease: critique and recommendations. Mov Disord 2008;23:2015-2025.

12. Hamilton M. The assessment of anxiety states by rating. Br J Med Psychol 1959;32:50-55

13. Hughes AJ, Daniel SE, Kilford L, Lees AJ. Accuracy of clinical diagnosis of idiopathic Parkinson's disease: a clinico-pathological study of 100 cases. J Neurol Neurosurg Psychiatry 1992;55:181-184. 
14. Brucki SM, Nitrini R, Caramelli P, Bertolucci PH, Okamoto IH. [Suggestions for utilization of the mini-mental state examination in Brazil]. Arq Neuropsiquiatr 2003;61:777-781.

15. Amorim P. Mini International Neuropsychiatric Interview (MINI): validation of a short structured diagnostic psychiatric interview. Rev Bras Psiquiatr 2000;22:106-115.

16. Moreno RA, Moreno DA. Escalas de depressão de Montgomery \& Åsberg (MADRS) e de Hamilton (HAM-D). Rev Psiquiatr Clin 1998;25:262-272.

17. Shear MK, Bilt JV, Rucci P, et al. Reliability and validity of a structured interview guide for the Hamilton Anxiety Rating Scale (SIGH-A). Depress Anxiety 2001; 13:166-178

18. Ebersbach G, Baas H, Csoti I, Mungersdorf M, Deuschl G. Scales in Parkinson's disease. J Neurol 2006;253:32-35

19. Hoehn MM, Yahr MD. Parkinsonism: onset, progression, and mortality. Neurology 1967;17:427-442.

20. McRae C, Diem G, Vo A, O'Brien C, Seeberger L. Schwab \& England: standardization of administration. Mov Disord 2000;15:335-336.

21. Nuti A, Ceravolo R, Piccinni A, et al. Psychiatric comorbidity in a population of Parkinson's disease patients. Eur J Neurol 2004;11:315-320.

22. Schiffer RB, Kurlan R, Rubin A, Boer S. Evidence for atypical depression in Parkinson's disease. Amer J Psychiatry 1988;145:1020-1022.

23. Starkstein SE, Robinson RG, Leiguarda R, Preziosi TJ. Anxiety and depression in Parkinson's disease. Behav Neurol 1993:6:151-154.

24. Lauterbach EC, Duvoisin RC. Anxiety disorders in familial parkinsonism. Am J Psychiatry 1991;148:274.

25. Henderson R, Kurlan R, Kersun JM, Como P. Preliminary examination of the comorbidity of anxiety and depression in Parkinson's disease. J Neuropsychiatry Clin Neurosci 1992;4:257-264.

26. Mondolo F, Jahanshahi M, Granà A, Biasutti E, Cacciatori E, Di Benedetto P. Evaluation of anxiety in Parkinson's disease with some commonly used rating scales. Neurol Sci 2007;28:270-275.

27. Riskind JH, Beck AT, Brown G, Steer RA. Taking the measure of anxiety and depression: validity of the reconstructed Hamilton scales. J Nerv Ment Dis 1987; 175:474-479.

28. Vazquez A, Jimenez-Jimenez FJ, Garcia-Ruiz P, Garcia-Urra D. "Panic attacks" in Parkinson's disease. A long-term complication of levodopa therapy. Acta Neurol Scand 1993;87:14-18.

29. Menza MA, Sage J, Marshall E, Cody R, Duvoisin R. Mood changes and "on-off" phenomena in Parkinson's disease. Mov Disord 1990;5:148-151.

30. Nissenbaum H, Quinn NP, Brown RG, Toone B, Gotham AM, Marsden CD. Mood swings associated with the 'on-off' phenomenon in Parkinson's disease. Psychol Med 1987;17:899-904

31. Kummer A, Teixeira AL. Neuropsychiatry of Parkinson's disease. Arq Neuropsiquiatr 2009;67:930-939.

32. Menza MA, Palermo B, DiPaola R, Sage Jl, Ricketts MH. Depression and anxiety in Parkinson's disease: possible effect of genetic variation in the serotonin transporter. J Geriatr Psychiatry Neurol 1999;12:49-52.

33. Kurlan R, Lichter D, Schiffer RB. Panic/anxiety in Parkinson's disease: yohimbine challenge [abstract]. Neurology 1989;39:421.

34. Schrag A, Barone P, Brown RG, et al. Depression rating scales in Parkinson's disease: critique and recommendations. Mov Disord 2007:22:1077-1092. 